\title{
Deep Eutectic Solvents Based Ultrasonic Extraction of Polysaccharides from Edible Brown Seaweed Sargassum horneri
}

\author{
Jinggui Nie, Danting Chen and Yanbin Lu*(1) \\ Institute of Seafood, Key Laboratory of Aquatic Products Processing of Zhejiang Province, \\ Zhejiang Gongshang University, Hangzhou 310012, China; niejinggui@163.com (J.N.); \\ cdt1144173162@163.com (D.C.) \\ * Correspondence: luyanbin@zjgsu.edu.cn; Tel.: +86-571-87103135
}

Received: 21 May 2020; Accepted: 12 June 2020; Published: 16 June 2020

check for updates

\begin{abstract}
In this work, a method for ultrasonic extraction of polysaccharides from Sargassum horneri using deep eutectic solvents was proposed. The studied deep eutectic solvents were composed of choline chloride, 1,2-propanediol and water. Based on the single-factor experiment results, four experimental factors were systematically evaluated, giving the optimal extraction conditions as follows: molar ratio of choline chloride to 1,2-propanediol of 1:2, water content of $30 \%(\mathrm{v} / \mathrm{v})$, solid-liquid ratio of $1: 30(\mathrm{~g} / \mathrm{mL})$, and the extraction temperature of $70{ }^{\circ} \mathrm{C}$. Fourier transform infrared spectroscopy and $X$-ray diffraction were utilized to investigate changes in the chemical characteristic of extracted polysaccharides. The results indicated that deep eutectic solvents had stronger protein and calcium carbonate removal ability than that of a conventional hot water extraction method. Moreover, in vitro antioxidant activity tests exhibited that the obtained polysaccharides had significant inhibition effects on DPPH and ABTS radicals. The proposed deep eutectic solvents assisted ultrasonic extraction protocol was considered to be a green, fast and effective protocol for extracting polysaccharides from Sargassum horneri.
\end{abstract}

Keywords: Sargassum horneri; deep eutectic solvents; ultrasonic extraction; polysaccharides; antioxidant activity

\section{Introduction}

Sargassum horneri, an edibal brown seaweed, was one of the main components in the subtidal seaweed flora extensively distributed in East China Sea, which was rich in dihomo-gamma-linolenic acid and polysaccharides [1]. Among these compounds, polysaccharides had been recognised as the main active components which had many functions, including antivirus, antioxidant, and anti-aging activities [2,3]. Due to the potential bioactivity of polysaccharides, the development of efficient extraction and purification of polysaccharides from S. horneri, is of great importance. Generally, the traditional extraction protocol of polysaccharides was the water-boiling method. However, under high temperature, many components were dissolved and might lose their activity. Therefore, researchers had developed other auxiliary protocols, such as auxiliary water enzyme, ultrasonic-assisted extraction, microwave-assisted extraction, and vacuum extraction, to extract polysaccharides more quickly and efficiently in recent years [3]. However, in the process to extract polysaccharides from S. horneri it is necessary to use organic solvents which have several disadvantages, such as toxicity and unsafety [4]. In addition, scientists had also been committed to designing new environmentally friendly green extraction solvents that met technical and economic needs [5]. In recent years, there had been a significant increase in the use of ionic liquids (ILs) as green solvents for the extraction and 
purification of natural bioactive components [6,7]. However, due to the potential toxicity and low biodegradability of ILs, there was a concern that it might have a potential impact on human health and the environment [8]. Moreover, the synthesis and purification of ILs required a higher cost than ordinary solvents $[9,10]$. To overcome these drawbacks of ILs, it was imperative to find alternative solvents to replace ILs.

Recently, it was found that the use of deep eutectic solvents (DESs) as a green alternative to replace traditional organic solvent had got great development [11]. Their physicochemical properties were very similar to the ILs [12]. DESs could be easily prepared from natural and available compounds in a very simple manner by mixing and heating. From the point of view of sustainable chemistry, these characteristics made it very attractive [13]. It had been successfully used in the extraction of flavonoids [14], carrageenan [15], phenolic acids [16], alkaloids [17] and other active components from traditional Chinese medicine. As we know, ultrasonic crushing could greatly speed up the extraction process, shorten the extraction time and improve the extraction yield [18]. Moreover, DESs had the advantages of biodegradability, low cost, and simple synthesis [19]. Therefore, the development of DESs-assisted ultrasonic extraction of polysaccharides was a promising method. To the best of our knowledge, there had been no detailed study of the use of DESs-assisted ultrasonic extraction of polysaccharides from $S$. horneri. Therefore, the purpose of this study was to establish an environmental friendly and efficient method for extracting polysaccharides from S. horneri. The extraction process was carefully optimized. At the same time, the chemical properties and antioxidant activity of extracted S. horneri polysaccharides were also studied.

\section{Results and Discussion}

\subsection{Optimization of the DESs-Assisted Ultrasonic Extraction of Polysaccharides}

\subsubsection{Effect of Molar Composition of Studied DESs}

Generally, DESs are composed of a hydrogen bond acceptor with a donor in a certain proportion. Among them, the physicochemical properties of DESs, including viscosity, solubility, and most importantly, polarity, will have great influence on the extraction yield of the targeted components [9-11]. Considering the polarity and solubility of polysaccharides, the selected DESs were composed of hydrophilic choline chloride and 1,2-propanediol accroding to the literatures [13-18]. Thus, different choline chloride and 1,2-propanediol molar ratios could affect the viscosity and polarity of the DESs. In this work, the experiments of extracting polysaccharides with DESs by different molar ratios were carried out, and the results were shown in Figure 1A. It was obvious that the extraction yield of polysaccharides increased first with the increase in the molar ratio of choline chloride and 1,2-propanediol. When the molar ratio reached 1:2, the extraction yield was the largest. Because increasing the proportion of 1,2-propanediol in DESs not only increased its viscosity but also increased the surface tension. Further increasing the ratio of 1,2-propanediol in DESs might reduce the interaction of 1,2-propanediol with choline chloride and decrease the extraction yield [20]. Therefore, the molar ratio of 1:2 was selected as the best extraction condition for preparation of DESs. 

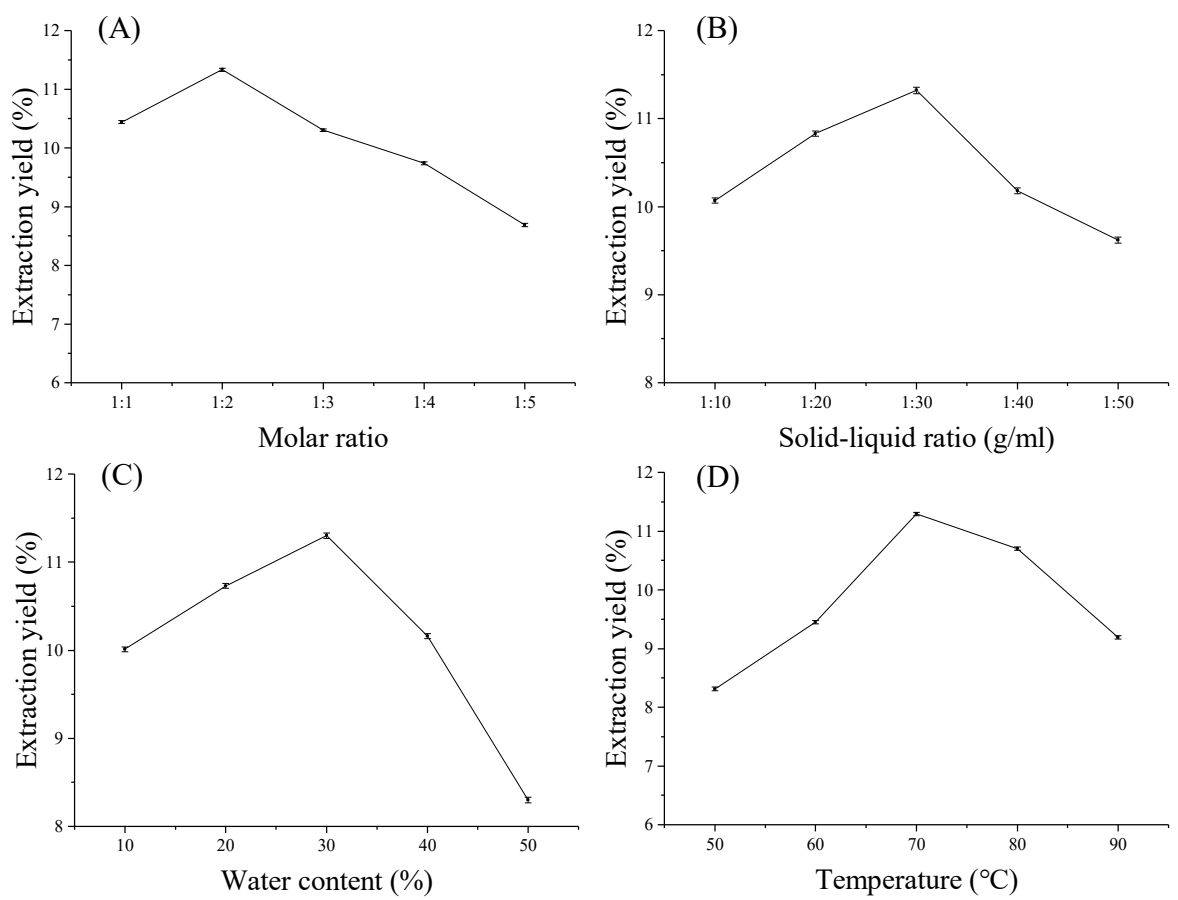

Figure 1. (A) Effect of different molar ratios on the extraction yield of crude polysaccharides. Expeimental conditions: water content of $30 \%(\mathrm{v} / \mathrm{v})$, solid-liquid ratio of 1:30 (g/mL), extraction temperature of $70{ }^{\circ} \mathrm{C}$, sonication time of $30 \mathrm{~min}$, amplitude level of $40 \%$; (B) Effect of different solid-liquid ratios on the extraction yield of crude polysaccharides. Expeimental conditions: molar ratio of $1: 2$, water content of $30 \%(\mathrm{v} / \mathrm{v})$, extraction temperature of $70{ }^{\circ} \mathrm{C}$, sonication time of $30 \mathrm{~min}$, amplitude level of $40 \%$; (C) Effect of different water content on the extraction yield of crude polysaccharides. Expeimental conditions: molar ratio of 1:2, solid-liquid ratio of 1:30 (g/mL), extraction temperature of $70{ }^{\circ} \mathrm{C}$, sonication time of $30 \mathrm{~min}$, amplitude level of 40\%; (D) Effect of different extraction temperature on the extraction yield of crude polysaccharides. Experimental conditions: molar ratio of 1:2, solid-liquid ratio of $1: 30(\mathrm{~g} / \mathrm{mL})$, water content of $30 \%(\mathrm{v} / \mathrm{v})$, sonication time of $30 \mathrm{~min}$, amplitude level of $40 \%$. Each experiment was carried out in triplicate.

\subsubsection{Effect of Solid-Liquid Ratio}

Generally, the solid to liquid ratio (sample-solvent ratio) is a key factor in extraction yield. In this study, different solid to liquid ratios were tested, including $10,20,30,40$ and $50 \mathrm{~g} / \mathrm{mL}$, and the results were shown in Figure 1B. The extraction yield of polysaccharides increased with the increase in solid-liquid ratio. When the solid-liquid ratio reached 1:30 $(\mathrm{g} / \mathrm{mL})$, the extraction yield of polysaccharides began to decline. This may be because the extraction equilibrium can be reached quickly with a small amount of extraction solvent. Although a large amount of extraction solvent increased the leaching rate of the target compound, it also caused the waste of the extraction solvent and complicated the extraction process [21]. Therefore, the solid-liquid ratio of 1:30 was selected for the extraction of polysaccharides from S. horneri.

\subsubsection{Effect of Water Content}

The water content (volume ratio, \%) of the DESs aqueous solution affects the viscosity and increases its polarity. Therefore, the extraction yield seems to depend largely on the water content [5]. In this study, experiments were carried out to extract polysaccharides with DESs at different water contents, and the results were shown in Figure 1C. The extraction yield of polysaccharides increased with the increase in water content. When the water content reached $30 \%(\mathrm{v} / \mathrm{v})$, the extraction yield reached the maximum. Further increasing the water content, the extraction yield of polysaccharides began to decrease. This might be attributed to the fact that low water content was difficult to penetrate into 
plant cells to achieve high extraction yields. However, high water content would increase the polarity of the mixture and reduce the interaction between molecules [22]. Therefore, in this work, the water content $30 \%(\mathrm{v} / \mathrm{v})$ was selected as the best extraction condition for the extraction of polysaccharides from S. horneri.

\subsubsection{Effect of Temperature}

The extraction temperature is a crucial factor on extraction yield. In this study, the effects of different extraction temperatures on the polysaccharides yield were tested, including 50, 60, 70, 80 and $90^{\circ} \mathrm{C}$, and the results were shown in Figure $1 \mathrm{D}$. When the temperature was set at $70^{\circ} \mathrm{C}$, the extraction yield reached the maximum value. This might be due to the fact that increase in temperature could produce a higher mass transfer rate and solvent diffusion rate, thus improving the extraction yield. However, higher temperature might also cause the thermal degradation of target compounds [23]. Hence, the temperature $70^{\circ} \mathrm{C}$ was optimized in this work.

From the above evaluation, the optimal extraction condition for the studied DESs-assisted ultrasonic extraction of polysaccharides from $S$. horneri could be as follows: a molar ratio of 1:2, a solid-liquid ratio of 1:30 (g/mL), a water content of $30 \%(\mathrm{v} / \mathrm{v})$, and an extraction temperature of $70{ }^{\circ} \mathrm{C}$. Thus, we performed three parallel experiments under these conditions. The results showed that the relative extraction yield of crude polysaccharides from S. horneri was $11.31 \%$.

\subsubsection{Comparison with the Conventional Hot Water Extraction}

In this work, the polysaccharides from S. horneri were also extracted by the conventional hot water method, producing the relative yield of $13.52 \%$. Although the relative yield of crude polysaccharides by hot water extraction was a little bit higher than that of DESs-assisted ultrasonic extraction $(11.31 \%)$, the proposed DESs extraction method only cost $30 \mathrm{~min}$ for each ultrasonic process, saving $75 \%$ of time consumption and greatly enhancing the productivity. Moreover, the temperature of ultrasonic extraction was optimized at $70^{\circ} \mathrm{C}$, which was milder than that of water extraction method, and might not damage the structure of polysaccharides present in S. horneri. Therefore, DESs exhibited as a promising solvent alternative for the extraction of polysaccharides from brown seaweeds.

\subsection{Characterization of Extracted Polysaccharides}

\subsubsection{Infrared Spectrometry Analysis}

Fourier transform infrared (FT-IR) spectrum of polysaccharides extracted by DESs and hot water are shown in Figure 2A. In both spectra, the absorption peaks at 3331, 2934, 1747, 1411, and $1036 \mathrm{~cm}^{-1}$ are characteristic peaks in polysaccharides [24-27]. The broad and strong absorption peak at $3331 \mathrm{~cm}^{-1}$ is the stretching vibration peak of O-H. The small peak at $2934 \mathrm{~cm}^{-1}$ is the C-H stretching vibration peak on the sugar ring or branch. The peak at $1747 \mathrm{~cm}^{-1}$ should be a $\mathrm{C}=\mathrm{O}$ stretching vibration in the amide group. The peak at $1411 \mathrm{~cm}^{-1}$ should be a C-H stretching vibration peak. The peak at $1036 \mathrm{~cm}^{-1}$ may be a C-O-C stretching vibration peak.

However, it can be clearly seen from Figure 2A that the polysaccharides extracted by DESs has no obvious absorption peak around $1310 \mathrm{~cm}^{-1}$, while the polysaccharides extracted by hot water has a sharp peak. Generally, the absorption peak at $1310 \mathrm{~cm}^{-1}$ could be attributed to the C-N telescopic vibration absorption peak [28]. The polysaccharides extracted by DESs are less contamination from protein than those extracted by hot water. The high purity of the $S$. horneri polysaccharides extracted by the DESs method can be attributed to the hydrogen bonding interaction between the DESs and the polysaccharides components [29]. The competitive hydrogen bond formation between DESs and carbohydrate leads to the destruction of the intramolecular hydrogen bond network, thereby weakening the hydrogen bond interactions in the S. horneri. As a result, the polysaccharides dissolved in DESs were separated from the protein. Therefore, we can infer that the DESs' extracted S. horneri polysaccharides have obvious deproteinization effect compared with the hot water extracted polysaccharides. 

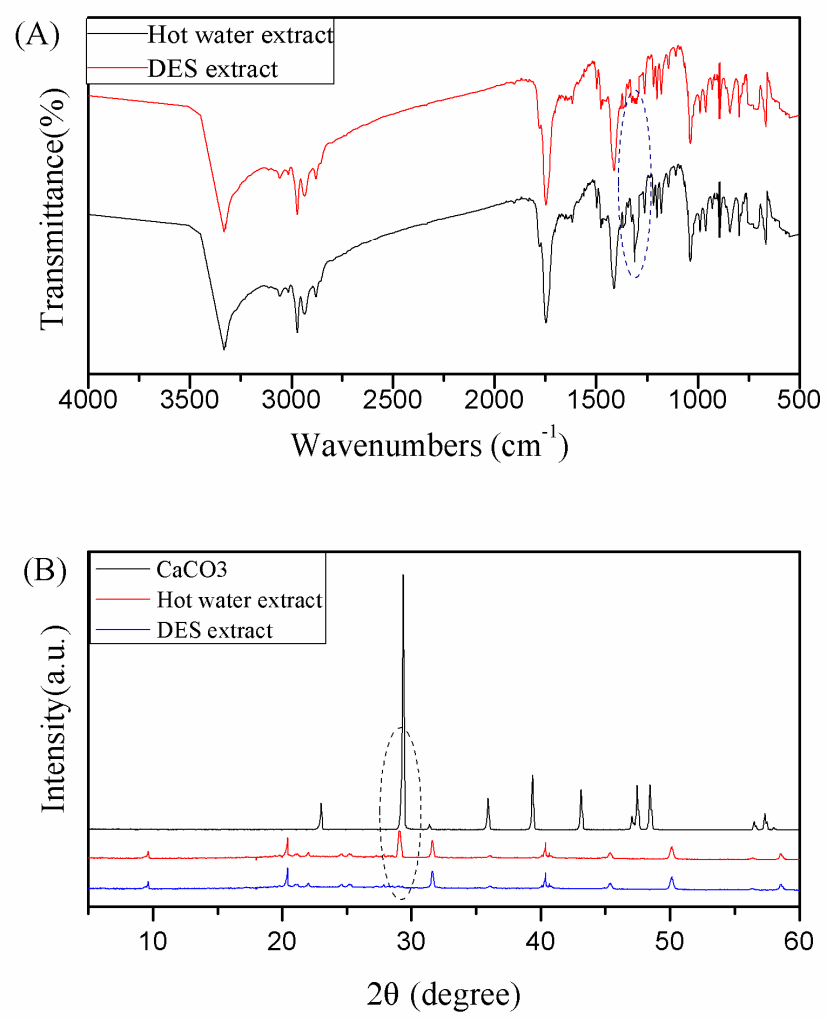

Figure 2. (A) The FT-IR spectrum of hot water extracted $S$. horneri polysaccharides and DESs extracted S. horneri polysaccharides; (B) X-ray curve of $\mathrm{CaCO}_{3}$, hot water extracted $S$. horneri polysaccharides and DESs extracted $S$. horneri polysaccharides.

\subsubsection{X-Ray Diffraction Analysis}

The X-ray has a wavelength in the range of 0.01 to $10 \mathrm{~nm}$, which is equivalent to the atomic distance in the crystal, so that when X-ray passes through the crystal, it can cause electron vibration in the crystal. Thus it can be used to determine the configuration of the crystal [30]. In this study, X-ray diffraction (XRD) analysis was performed to determine the crystal structure and relative crystallinity of the polysaccharides obtained from S. horneri by both DESs-based extraction and conventional hot water extraction method. The XRD patterns of the polysaccharides extracted by DESs, the polysaccharides extracted by hot water, and $\mathrm{CaCO}_{3}$ are shown in Figure 2B. It can be seen that the DESs-extracted sample exhibits typical diffraction peaks at $2 \theta=9.64^{\circ}, 20.42^{\circ}, 29.06^{\circ}, 31.62^{\circ}, 40.38^{\circ}$ and $50.12^{\circ}$, which is the lattice type of the general polysaccharides. The XRD pattern of the polysaccharides extracted by DESs is almost the same as the polysaccharides obtained by the hot extraction method. However, the diffraction peak of $\mathrm{CaCO}_{3}$ at about $2 \theta=29.36^{\circ}$ is not observed in the polysaccharides extracted from DESs. This may be because the polysaccharides extracted by DESs do not contain $\mathrm{CaCO}_{3}$. Further, the crystallinity index of the sample was calculated according to the Segal method. The CrI of the S. horneri polysaccharides was calculated by the DESs method to be $65.87 \%$, which was calculated to be $54.14 \%$ by the conventional hot water extraction method. The increase in CrI after the DESs treatment was due to the removal of $\mathrm{CaCO}_{3}$ in the polysaccharides. This may be because choline chloride in DESs can directly invade the internal structure of $S$. horneri, and then directly contact calcium carbonate and protein to have a reaction, leading to both deproteinization and demineralization. Therefore, we can infer that the $S$. horneri polysaccharides extracted by the proposed DESs method have a more significant mineral-removing effect than that of conventional hot water extraction method. 


\subsection{Antioxidant Activity of Extracted Polysaccharides}

The DPPH free radical is a stable free radical that is widely used as a tool for estimating the free-radical-scavenging activities of antioxidants [31]. The antioxidant mechanism of DPPH radical scavenging is related to the acceptability of DPPH radical to hydrogen. DPPH is converted to DPPH-H, a non-free radical form, from hydrogen provided by antioxidants [32]. Figure 3A exhibited DPPH radical scavenging activity of polysaccharides extracted by DESs and compared with BHT as positive control. Under the experimental conditions, with the increase in concentration, the DPPH free-radical-scavenging effect of $S$. horneri polysaccharides was gradually enhanced. When the polysaccharides concentration increased from 0.5 to $3 \mathrm{mg} / \mathrm{mL}$, the DPPH radical scavenging yield increased from $32.36 \%$ to $67.82 \%$. The results showed that the $S$. horneri has significant DPPH removal efficiency. This may be because the $S$. horneri polysaccharides can eliminate excess oxygen radicals produced in vitro by blocking free radical reaction chains, so the polysaccharides have an obvious scavenging effect on DPPH free radicals.

The ABTS assay is a well-established method for measuring the antioxidant capacity of potential antioxidants. This is because ABTS free radicals can be oxidized to free radical cations $\left(\mathrm{ABTS}^{+}\right)$for measuring the antioxidant capacity of water-soluble and fat-soluble food samples [33]. Figure 3B exhibited ABTS radical scavenging activity of polysaccharides extracted by DESs and compared with ascorbic acid which was used as positive control. When the mass concentration was $0.5-3.0 \mathrm{mg} / \mathrm{mL}$, with the increase of concentration, the removal yield of $S$. horneri polysaccharides showed an obvious upward trend. When the mass concentration of the polysaccharides was $3 \mathrm{mg} / \mathrm{mL}$, the ABTS free radical clearance yield reached $71.28 \%$. However, the scavenging yield of ascorbic acid on ABTS radical was stable at about $90 \%$. The removal yield was better than the S. horneri, and did not change with the increase in concentration. Therefore, we can only say the $S$. horneri polysaccharides have a certain ABTS free-radical scavenging ability and can be used as an antioxidant product for future research.
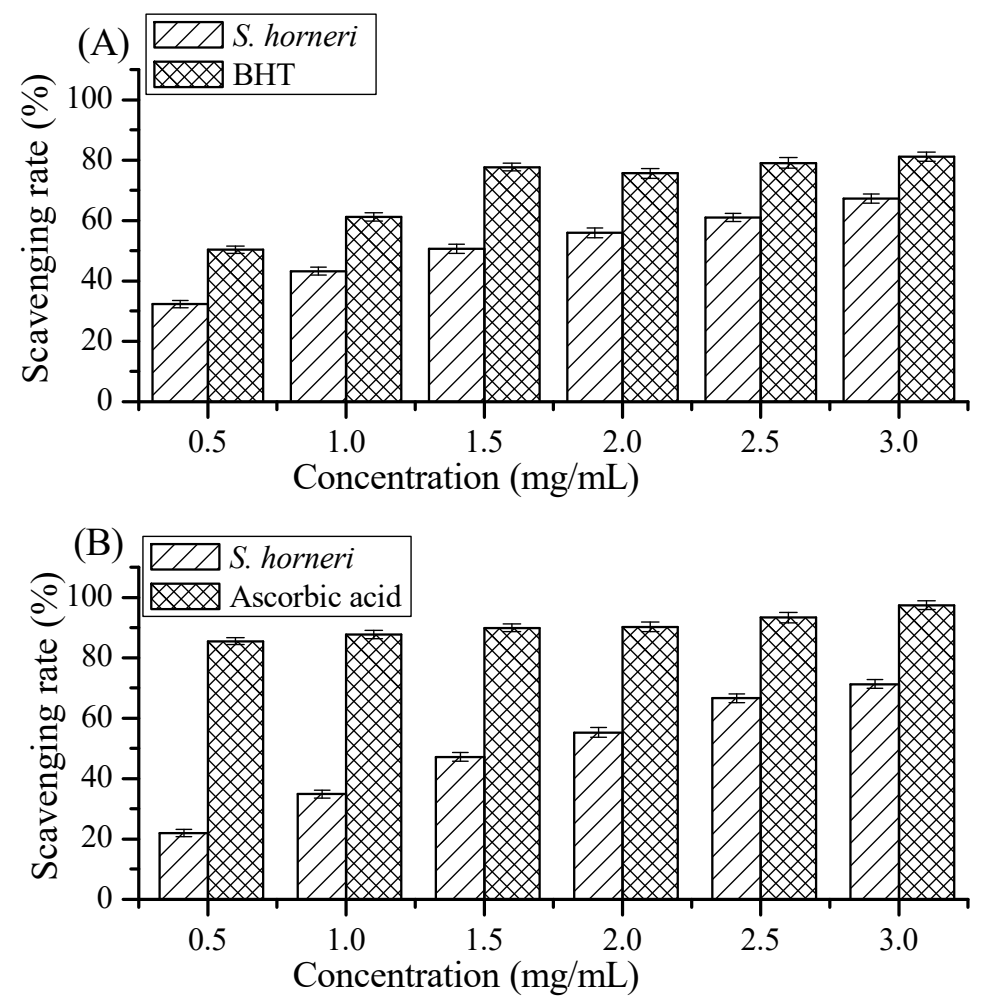

Figure 3. (A) Scavenging of DPPH free radicals by S. horneri polysaccharides; (B) Scavenging of ABTS free radicals by $S$. horneri polysaccharides. 


\section{Materials and Methods}

\subsection{Materials}

The materials of S. horneri were purchased from Dong Tou county (Zhejiang, China) and identified by Prof. Juanjuan Chen from College of Marine Sciences, Ningbo University. The choline chloride (dried before use), ethanol and 1,2-propanediol were analytically pure and purchased from Xi Long Chemical Co. (Guangdong, China). The reagents used for antioxidant activity tests, including ascorbic acid (Vc), 2,6-ditert-butyl-4-methyl phenol, 1,1-diphenyl-2-picrylhydrazyl (DPPH), and 2-2-azino-bis-(3-ethyl-benzthia-zoline-6-sulfonic acid) (ABTS), were purchased from Sigma-Aldrich (Shanghai, China).

\subsection{Ultrasonic-Assisted Extraction of Polysaccharides Using DESs}

\subsubsection{Preparation of DESs}

DESs was prepared by mixing choline chloride and 1,2-propanediol in different ratios accordingly to the literature $[10,11]$. First, the mixture was prepared according to their ratio $(1: 1$ to $1: 5)$ and stored in a reaction flask. Then, it was continuously stirred for $60 \mathrm{~min}$ under the temperature of $80{ }^{\circ} \mathrm{C}$ until a clear homogeneous solution was obtained.

\subsubsection{Ultrasonic-Assisted Extraction of Polysaccharides by DESs}

A Sonics Vibra-Cell VCX-500 sonicator (Sonics and Materials Inc., CT, USA) equipped with a Ti-Al-V probe $(1.3 \mathrm{~cm}$ diameter) was employed for ultrasound-assisted extraction. The maximum of $500 \mathrm{~W}$ output power and $20 \mathrm{kHz}$ of frequency could be provided by the sonicator. The amplitude control unit allowed the probe to be set at any desired level in the 10\%-100\% range of the nominal power.

In this work, $10 \mathrm{~g}$ of $S$. horneri powder was weighed and added with different extraction solvents accordingly for all the ultrasonic experiments. Consequently, the effects of choline chloride and 1,2-propanediol molar ratio (1:1-1:5), water content of the studied DESs $(10 \%-50 \%)$, solid-liquid ratio (sample-solvent ratio, 1:10-1:50), and extraction temperature $\left(50-90^{\circ} \mathrm{C}\right.$ ) on the yield of polysaccharides were carefully studied and evaluated by a single-factor experiment. The amplitude level of $40 \%$ and ultrasonic time of $30 \mathrm{~min}$ were optimized and selected for all the ultrasonic extractions. Afterwards, the obtained extract was precipitated by adding of absolute ethanol. After centrifugation at $8000 \mathrm{r} / \mathrm{min}$ for $10 \mathrm{~min}$, the precipitate was taken out and finally washed twice with absolute ethanol to remove colored substances and other impurities. The precipitate was dried in a vacuum desiccator for $24 \mathrm{~h}$. Three repeated extraction tests were performed.

In this work, the relative yield of crude polysaccharides was determined by phenol-sulfuric acid method using $D$-glucose as the standard substance [34,35]. The extraction yield (\%) of polysaccharides was calculated as follows:

$$
\text { Yield }(\%)=\frac{\text { the crude polysaccharides content }(\mathrm{g})}{\text { weight of sample }(\mathrm{g})} \times 100 \%
$$

\subsection{Conventional Hot Water Extraction Method}

The dried S. horneri was crushed, screened 100 mesh, and treated by water extraction [36]. Briefly, $30 \mathrm{~g}$ crude materials of $S$. horneri powder was extracted with distilled water (the mass/volume ratio was 1:65) for $2 \mathrm{~h}$ under the temperature of $95^{\circ} \mathrm{C}$. The obtained extract was cooled, filtered and centrifuged at $8000 \mathrm{rpm}$ for $10 \mathrm{~min}$. The supernatant was concentrated to $180 \mathrm{~mL}$ by rotary evaporator. Then, the crude polysaccharides were obtained by precipitation using $80 \%$ ethanol and subsequent lyophylization. Three repeated extraction tests were performed. The relative yield of crude polysaccharides was also determined by the phenol-sulfuric acid method which described in Section 3.2.2. 


\subsection{Characterization of Extracted Polysaccharides}

The S. horneri polysaccharides obtained under the optimum conditions was characterized by the following methods.

Fourier transform infrared (FT-IR) spectra were recorded in the range of $4000-500 \mathrm{~cm}^{-1}$ using an FT-IR spectrometer (Thermo Scientific, Massachusetts, USA).

XRD patterns were recorded using a D/max-2500 X-ray diffractometer (Rigaku Denki, Tokyo, Japan) with $\mathrm{Cu} \mathrm{K} \alpha_{1}$ radiation $(\lambda=0.154 \mathrm{~nm})$ in a range from $5^{\circ}$ to $60^{\circ}$ at a scanning yield of $5^{\circ} / \mathrm{min}$ with a step interval of $0.02^{\circ}$. The relative crystallinity index (CrI) was calculated by the Segal method [37]

$$
\operatorname{CrI}(\%)=\frac{I_{110}-I_{a m}}{I_{a m}} \times 100
$$

where $I_{110}$ is the peak intensity of the diffraction for the (110) plane at $2 \theta \approx 20^{\circ}$ and $I_{a m}$ is the intensity of the amorphous diffraction at $2 \theta \approx 18^{\circ}$.

\subsection{Determination of Antioxidant Activity of Extracted Polysaccharides}

\subsubsection{DPPH Free Radical Clearance Yield Determination}

A total of $0.5 \mathrm{~mL}$ of samples $(0,0.5,1.0,1.5,2.0,2.5$, and $3.0 \mathrm{mg} / \mathrm{mL})$ was added to $3.0 \mathrm{~mL}$ of a $0.01 \%$ $(\mathrm{v} / \mathrm{v})$ ethanol solution of DPPH. Absorbance at $517 \mathrm{~nm}$ was measured after $30 \mathrm{~min}$. The scavenging activity of DPPH radical was calculated according to the following equation [32]

$$
\text { Scavenging effect }(\%)=\frac{A_{517}(\text { blank })-A_{517}(\text { sample })}{A_{517}(\text { blank })} \times 100
$$

where $A_{517}$ (blank) was the absorbance of the control (deionizedwater, instead of sample) and $A_{517}$ (sample) was the absorbance of the test sample mixed with reaction solution.

\subsubsection{ABTS Free Radical Scavenging Yield Determination}

The radical cation was prepared by mixing a $7 \mathrm{mM}$ ABTS stock solution with $2.45 \mathrm{mM}$ potassium persulfate $(1 / 1, \mathrm{v} / \mathrm{v})$ and leaving the mixture for $4-8 \mathrm{~h}$ until the reaction was completed and the absorbance was stable. The $\mathrm{ABTS}^{+}$solution was diluted in ethanol to an absorbance of $0.700 \pm 0.05$ at $734 \mathrm{~nm}$ for measurements. The photo metric assay was conducted on $0.9 \mathrm{~mL}$ of the ABTS ${ }^{+}$solution and $0.1 \mathrm{~mL}$ of isolated polysaccharides dissolved in a $\mathrm{MeOH}$ solution and mixed for $45 \mathrm{~s}$. Measurements were taken immediately at $734 \mathrm{~nm}$ after $1 \mathrm{~min}$. The antioxidative activity of the polysaccharides was calculated by determining the decrease in absorbance at different concentrations by using the following equation [38]:

$$
\text { Scavenging effect }(\%)=\frac{A_{C}-A_{T}}{A_{C}} \times 100
$$

Here, $A_{T}$ and $A_{C}$ are the respective absorbance of samples with and without polysaccharides.

\section{Conclusions}

In this study, a green and convenient method for extraction of polysaccharides from S. horneri based on DESs was proposed. The studied DESs were composed of choline chloride and 1,2-propanediol. Based on the single-factor experiment results, four experimental factors were systematically evaluated, giving the optimal extraction conditions as follows: molar ratio of choline chloride to 1,2-propanediol of $1: 2$, water content of $30 \%(\mathrm{v} / \mathrm{v})$, solid-liquid ratio of $1: 30(\mathrm{~g} / \mathrm{mL})$, and the extraction temperature of $70{ }^{\circ} \mathrm{C}$. The extraction yield of $S$. horneri polysaccharides reached $11.31 \%$ through the optimal extraction conditions. Additionally, FT-IR and X-ray diffraction were employed to analyze the characteristics of polysaccharides extracted from DESs and compared with the conventional hot water extraction. The polysaccharides extracted from $S$. horneri by DESs had obvious functions of removing proteins and minerals compared with hot water extraction. In vitro antioxidant experiments showed that the 
polysaccharides extracted from S. horneri had obvious antioxidant activity, and the scavenging ability of DPPH and ABTS radical reached $67.82 \%$ and $71.28 \%$, respectively. Therefore, S. horneri polysaccharides could be used as a potential natural antioxidant. This study provided a green and simple method for the extraction of polysaccharides in S. horneri, and revealed the great potential of DESs in the extraction of biopolymer from natural products.

Author Contributions: Y.L. conceived and designed the experiments, J.N., D.C. performed the experiments, J.N., D.C., Y.L. analyzed the data, J.N., D.C. wrote the paper, Y.L. reviewed and edited the paper. All authors have read and agreed to the published version of the manuscript.

Funding: This research was funded by Department of Science and Technology of Zhejiang Province (No. LGN18C200015).

Conflicts of Interest: The authors declare no conflict of interest.

\section{References}

1. Abdel-Fattah, A.F.; Hussein, M.D.; Salem, H.M. Some structural features of sargassan, a sulphated heteropolysaccharide from Sargassum linifolium. Carbohyd. Res. 1974, 12, 1995-1998. [CrossRef]

2. Pujol, C.A.; Ray, S.; Ray, B.; Damonte, E.B. Antiviral activity against dengue virus of diverse classes of algal sulfated polysaccharides. Int. J. Biol. Macromol. 2012, 51, 412-416. [CrossRef] [PubMed]

3. Liu, Y.; Sun, Y.; Huang, G. Preparation and antioxidant activities of important traditional plant polysaccharides. Int. J. Biol. Macromol. 2018, 111, 780-786. [CrossRef]

4. Tang, W.Y.; Li, G.Z.; Chen, B.Q.; Zhu, T.; Kyung, H.R. Evaluating ternary deep eutectic solvents as novel media for extraction of flavonoids from Ginkgo biloba. Sep. Sci. Technol. 2017, 52, 91-99. [CrossRef]

5. Bubalo, M.C.; Ćurko, N.; Tomašević, M.; Ganić, K.K.; Redovniković, I.R. Green extraction of grape skin phenolics by using deep eutectic solvents. Food. Chem. 2016, 200, 159-166. [CrossRef] [PubMed]

6. Ventura, S.P.M.; Silva, F.A.E.; Quental, M.V.; Mondal, D.; Freire, M.G.; Coutinho, J.A.P. Ionic-liquid-mediated extraction and separation processes for bioactive compounds: Past, present, and future trends. Chem. Rev. 2017, 117, 6984-7052. [CrossRef]

7. Passos, H.; Freire, M.G.; Coutinho, J.A. Ionic liquid solutions as extractive solvents for value-added compounds from biomass. Green Chem. 2015, 46, 4786-4815. [CrossRef]

8. Gao, F.; Liu, L.L.; Tang, W.Y.; Kyung, H.R.; Zhu, T. Optimization of chromatographic behaviors of quercetin using choline chloride-based deep eutectic solvents as HPLC mobile phase additives. Sep. Sci. Technol. 2018, 53, 397-403. [CrossRef]

9. Hayyan, M.; Looi, C.Y.; Hayyan, A.; Wong, W.F.; Hashim, M.A. In vitro and in vivo toxicity profiling of ammonium-based deep eutectic solvents. PLoS ONE 2015, 10, e0117934. [CrossRef]

10. Juneidi, I.; Hayyan, M.; Mohd Ali, O. Toxicity profile of choline chloride-based deep eutectic solvents for fungi andcyprinus carpiofish. Environ. Sci. Pollut. Res. 2016, 23, 7648-7659. [CrossRef]

11. Abbott, A.P.; Ahmed, E.I.; Harris, R.C.; Ryder, K.S. Evaluating water miscible deep eutectic solvents (DESs) and ionic liquids as potential lubricants. Green Chem. 2014, 16, 4156-4161. [CrossRef]

12. Kareem, M.A.; Mjalli, F.S.; Hashim, M.A.; Alnashef, I.M. Phosphonium-based ionic liquids analogues and their physical properties. J. Chem. Eng. Data 2010, 55, 4632-4637. [CrossRef]

13. Zdanowicz, M.; Wilpiszewska, K.; Spychaj, T. Deep eutectic solvents for polysaccharides processing. A review. Carbohyd. Polym. 2018, 200, 361-380. [CrossRef] [PubMed]

14. Duan, L.; Dou, L.L.; Guo, L.; Li, P.; Liu, E. Comprehensive evaluation of deep eutectic solvents in extraction of bioactive natural products. Acs Sustain. Chem. Eng. 2016, 4, 2005-2411. [CrossRef]

15. Das, A.K.; Sharma, M.; Mondal, D.; Prasad, K. Deep eutectic solvents as efficient solvent system for the extraction of K-carrageenan from Kappaphycus alvarezii. Carbohyd. Polym. 2016, 136, 930-935. [CrossRef] [PubMed]

16. Peng, X.; Duan, M.H.; Yao, X.H.; Zhang, Y.H.; Zhao, C.J.; Zu, Y.G. Green extraction of five target phenolic acids from Lonicerae japonicae flos with deep eutectic solvent. Sep. Purif. Technol. 2016, 157, 249-257. [CrossRef]

17. Tan, T.; Zhang, M.; Wan, Y.; Qiu, H. Utilization of deep eutectic solvents as novel mobile phase additives for improving the separation of bioactive quaternary alkaloids. Talanta 2016, 149, 85-90. [CrossRef] 
18. Chen, C.; You, L.J.; Abbasi, A.M.; Fu, X.; Liu, R.H. Optimization for ultrasound extraction of polysaccharides from mulberry fruits with antioxidant and hyperglycemic activity in vitro. Carbohyd. Polym. 2015, 130, 122-132. [CrossRef]

19. Lu, W.; Alam, M.A.; Pan, Y.; Wu, J.; Wang, Z.; Yuan, Z. A new approach of microalgal biomass pretreatment using deep eutectic solvents for enhanced lipid recovery for biodiesel production. Bioresour. Technol. 2016, 218, 123-128. [CrossRef]

20. Dai, Y.; Van, S.J.; Witkamp, G.J.; Verpoorte, R.; Choi, Y.H. Natural deep eutectic solvents as new potential media for green technology. Anal. Chim. Acta 2013, 766, 61-68. [CrossRef]

21. Wang, M.; Wang, J.; Zhang, Y.; Xia, Q.; Bi, W.; Yang, X. Fast environment-friendly ball mill-assisted deep eutectic solvent-based extraction of natural products. J. Chromatogr. A 2016, 1443, 262-266. [CrossRef]

22. Gutiérrez, M.C.; Ferrer, M.L.; Mateo, C.R.; Del, M.F. Freeze-drying of aqueous solutions of deep eutectic solvents: A suitable approach to deep eutectic suspensions of self-assembled structures. Langmuir 2009, 25, 5509-5515. [CrossRef] [PubMed]

23. Chen, R.; Yuan, L.; Hang, D.; Liu, Z.; Li, S.; Yang, S. Optimization of ultrasonic extraction process of polysaccharides from Ornithogalum caudatum ait and evaluation of its biological activities. Ultrason. Sonochem. 2012, 19, 1160-1168. [CrossRef] [PubMed]

24. Park, K.H.; Lee, K.Y.; Lee, H.G. Chemical composition and physicochemical properties of barley dietary fiber by chemical modification. Int. J. Biol. Macromol. 2013, 60, 360-365. [CrossRef] [PubMed]

25. Yan, H.; Xie, Y.; Sun, S.; Sun, X.; Ren, F.; Shi, Q. Chemical analysis of astragalus mongholicus polysaccharides and antioxidant activity of the polysaccharides. Carbohyd. Polym. 2010, 82, 636-640. [CrossRef]

26. Zhang, J.; Wang, Z.W. Soluble dietary fiber from canna edulis ker by-product and its physicochemical properties. Carbohyd. Polym. 2013, 92, 289-296. [CrossRef] [PubMed]

27. Ifuku, S.; Nogi, M.; Abe, K.; Yoshioka, M.; Morimoto, M.; Saimoto, H. Preparation of chitin nanofibers with a uniform width as alpha-chitin from crab shells. Biomacromolecules 2009, 10, 1584-1588. [CrossRef]

28. Zhu, Y.; Xiong, J.; Tang, Y.; Yu, Z. Eis study on failure process of two polyurethane composite coatings. Prog. Org. Coat. 2010, 69, 7-11. [CrossRef]

29. Huang, W.C.; Zhao, D.; Guo, N.; Xue, C.; Mao, X. Green and facile production of chitin from crustacean shells using a natural deep eutectic solvent. J. Agric. Food. Chem. 2018, 66, 11897-11901. [CrossRef]

30. French, A.D.; And, J.W.B. Computer Modeling of Carbohydrates. ACS Sym. Ser. 1990, 430, $20-30$.

31. Fenglin, H.; Ruili, L.; Bao, H.; Liang, M. Free radical scavenging activity of extracts prepared from fresh leaves of selected chinese medicinal plants. Fitoterapia 2004, 75, 14-23. [CrossRef] [PubMed]

32. Jin, L.; Guan, X.; Liu, W.; Zhang, X.; Yan, W.; Yao, W. Characterization and antioxidant activity of a polysaccharide extracted from Sarcandra glabra. Carbohyd. Polym. 2012, 90, 524-532. [CrossRef] [PubMed]

33. Huang, D.; Ou, B.; Prior, R.L. The chemistry behind antioxidant capacity assays. J. Agric. Food. Chem. 2005, 53, 1841-1856. [CrossRef] [PubMed]

34. Dubois, M.; Gilles, K.A.; Hamilton, J.K.; Rebers, P.A.; Smith, F. Colorimetric Methods for Determination of Sugars and Related Substances. Anal. Chem. 1956, 28, 350-356. [CrossRef]

35. Wang, S.; Dong, X.; Tong, J. Optimization of enzyme-assisted extraction of polysaccharides from alfalfa and its antioxidant activity. Int. J. Biol. Macromol. 2013, 62, 387-396. [CrossRef] [PubMed]

36. Shao, P.; Chen, X.; Sun, P. Chemical characterization, antioxidant and antitumor activity of sulfated polysaccharide from Sargassum horneri. Carbohyd. Polym. 2014, 105, 260-269. [CrossRef]

37. Segal, L.; Creely, J.J.; Martin, A.E.; Conrad, C.M. An empirical method for estimating the degree of crystallinity of native cellulose using the x-ray diffractometer. Text. Res. J. 1959, 29, 786-794. [CrossRef]

38. Lee, B.W.; Jin, H.L.; Sang, W.G.; Moon, Y.H.; Park, K.H. Selective ABTS radical-scavenging activity of prenylated flavonoids from Cudrania tricuspidata. Biosci. Biotech. Biochem. 2006, 70, 427-432. [CrossRef]

(C) 2020 by the authors. Licensee MDPI, Basel, Switzerland. This article is an open access article distributed under the terms and conditions of the Creative Commons Attribution (CC BY) license (http://creativecommons.org/licenses/by/4.0/). 